\title{
MASSIFICAR SEM DEMOCRATIZAR: O EXCESSO QUE OPRIME
}

\author{
Kleber Vieira Pina ${ }^{1}$
}

\begin{abstract}
RESUMO: Este artigo pretende explorar um processo de exclusão que tem surgido graças ao modelo de expansão da educação superior adotado pelo Estado brasileiro. Análises realizadas acerca do crescimento histórico do número de matrículas e composição do sistema, bem como do tema da exclusão social e opressão, sugerem que as políticas nacionais pautadas pelo estímulo à iniciativa privada têm mantido, e não reduzido, como se divulga, a distância entre a elite nacional e as camadas inferiores da sociedade. É proposto que um modelo de oferta capaz de promover a cidadania e reduzir as desigualdades não pode se orientar pelas leis do mercado, já que estas tendem a estimular a concorrência entre indivíduos e, assim, mostram-se incapazes de promover reduçóes significativas de diferenças sociais.
\end{abstract}

Palavras-chave: Educação superior. Política educacional. Exclusão social.

\section{ACCESS EXPANSION WITHOUT DEMOCRATIZE: EXCESS THAT OPPRESSES}

\begin{abstract}
This article aims to explore the process of exclusion that has emerged due to the expansion of the higher education model adopted by the Brazilian State. Analyses of the historical growth of the number of registrations and the composition of the system, as well as the subject of social exclusion and oppression, suggest that national policies oriented at stimulating private initiative have maintained the gap between the national elite and the other social classes, instead of reducing it, as the State has claimed. It is proposed that a supply-based model able to promote citizenship and reduce inequalities cannot be guided by the laws of the market, since these tend to stimulate competition between individuals and thus are unable to promote significant reductions of social differences.
\end{abstract}

Keywords: Higher education. Educational policy. Social exclusion.

\footnotetext{
${ }^{1}$ Universidade Católica de Brasília, Programa de Pós-Graduação Stricto Sensu em Educação Brasília (DF), Brasil. E-mail: kleberpinaucb@gmail.com

DOI: 10.1590/ES0101-73302017101664
} 


\title{
MASSIFICATION SANS DÉMOCRATISATION: L'EXCÈS QUI OPPRIME
}

RESUME: Cet article propose d'explorer le développement de l'exclusion qui émerge grâce au modèle d'expansion de l'enseignement supérieur adopté par l'État brésilien. Les analyses sur la croissance historique du nombre d'élèves et la composition du système, ainsi que l'objet de l'exclusion sociale et de l'oppression, suggèrent que les politiques nationales orientées à stimuler l'initiative privée ont maintenu et pas réduit comme on divulgue, la distance entre l'élite nationale et les couches inférieures de la société. Il est proposé qu'un modèle d'offre capable de promouvoir la Citoyenneté et de réduire les inégalités ne puisse pas être orienté par les lois du marché, puisqu'elles ont tendance à stimuler la concurrence entre les individus et sont incapables de promouvoir des réductions significatives des différences sociales.

Mots-clés: Éducation supérieure. Politique de l'éducation. Exclusion sociale.

\section{Introdução}

\begin{abstract}
Esforço-me para indicar da forma mais explícita que uma universidade, como todas as outras instituiçóes humanas - como a Igreja, como governos, como organizaçóes filantrópicas - não é alheia, mas componente do tecido social mais abrangente de uma determinada época. (FLEXNER, 1930, p. 3)
\end{abstract}

A ssim, Abraham Flexner (1930) iniciou sua abordagem sobre o que, em sua opinião e seu tempo, viria a constituir uma universidade moderna. Flexner se opôs declaradamente a outro importante pesquisador desse assunto, o Cardeal Newman, seu antecessor, para quem "o conhecimento [gerado e disseminado pelas universidades] deveria encerrar-se em si mesmo" (CARDINAL NEWMAN, 1873, p. 103). Para Flexner, sem a pretensão apriorística de uma utilidade prática, a universidade compunha ativamente a vida social moderna, por se comportar, ao mesmo tempo, como indutora e paciente das modificaçóes que ocorrem no ambiente em que está inserida.

Ambos os posicionamentos se polarizam em face do tipo de saber que a universidade, enquanto organizaçáo social, deveria ser capaz de elaborar: ou o resultado de seus esforços ficaria encastelado entre seus muros, sendo a pura geração de novos saberes sua própria recompensa, ou ela própria se situaria como produtora e indutora de um tipo específico de conhecimento, baconiano em sua essência, regido por uma filosofia da utilidade (KERR, 1966). Pode-se dizer que esse último 
alcançou ampla vantagem sobre o primeiro no mundo ocidental, industrializado e capitalista, propagando-se por todo o globo como padráo a ser seguido.

É, dessa forma, que, na atualidade, o acesso ao ensino superior dilatou-se em muitos países, sejam ricos ou em desenvolvimento (SERAFIM, 2011), por meio de políticas expansionistas com foco na oferta, motivadas pelo princípio da igualdade de oportunidades para todos e complementadas com políticas de equidade capazes de corrigir eventuais distorçóes.

Trow (1970) e Weis e Dolby (2012) perceberam uma tendência nesse movimento expansionista que parte da educação superior como privilégio, destinada a poucos, em direção a um direito universal ressignificado como elemento potencializador da mobilidade social e sob a plena responsabilidade de cada indivíduo, no que tange à sua obtenção.

Surgindo da transição de um estágio da educação superior como privilégio em direção à sua universalização, está a massificação da oferta de vagas ${ }^{1}$, com tendências predominantemente liberais que, em linhas gerais, parte dos pressupostos, usualmente verdadeiros, de que:

1. há uma imensa demanda populacional a ser atendida;

2. essa demanda vê a consecuçáo de um curso superior como porta de acesso para melhores condiçóes de vida;

3. o Estado se vê como incapaz de, pelo menos em um primeiro momento, suprir tal demanda de forma universal, ou não considera esta uma política viável se abordada por um prisma puramente econômico; e

4. existem pressôes internas e externas que, se por um lado exigem maior capacitação da populaçáo como forma de elevar o contingente de mão de obra disponível para o processo produtivo de bens e serviços, por outro tendem a precarizar esse mesmo contingente.

No caso brasileiro, o processo de massificação da educação superior está em pleno curso. Nossa particularidade, entretanto, que pode ser compartilhada com outros países latino-americanos, está na opção por realizar esse alargamento de matrículas, abordando o problema apenas pelo prisma da oferta, por um modelo misto de oferecimento de vagas, pelos setores público e privado, mas com clara tendência à estruturação de um sistema essencialmente privado de ensino que se pauta pela tarefa de formar trabalhadores especializados.

Neste artigo, serão abordadas as incongruências desse modelo que, em um paradoxo apenas aparente, tende a enxergar a universalizaçấo da educação terciária como panaceia para as disparidades sociais, sem, entretanto, nas conclusōes do autor, ter a real possibilidade de obter sucesso nessa empreitada. Para 
tanto, serão analisados o crescimento histórico do número de matrículas e a composição do sistema brasileiro de educação, bem como o tema da exclusão social e da opressão.

Propóe-se, afinal, que as políticas nacionais pautadas pelo estímulo à iniciativa privada têm mantido, e não reduzido, como se divulga, a distância entre a elite nacional e as camadas mais baixas da sociedade. Sustenta-se, também, que apenas um sistema que enfatize menos a educação como mercadoria, percebida como um bem de serviço a ser ofertado em um determinado mercado de consumo, e que priorize suas potencialidades emancipatórias, pela real observação das demandas sociais, pode, de fato, promover a redução das diferenças entre indivíduos.

\section{Educação para o desenvolvimento: rumo à massificação}

A palavra desenvolvimento tem amplo lastro. No caso brasileiro, o desenvolvimento econômico, no discurso político, manteve, ao longo dos tempos, estreita relação com o desenvolvimento social, e é assim que Abdi e Guo (2008), ao abordarem os vários significados dessa segunda versão, afirmam compreender todas as formas de vantagens econômicas, políticas, educacionais, tecnológicas, emocionais e outras que, direta ou indiretamente, podem afetar a vida das pessoas.

Considera-se, ainda, que há uma forte associação entre o ensino superior e o desenvolvimento científico e tecnológico de uma naçáo (LOBO, 2011) e que tal desenvolvimento, quando imbricado às políticas nacionais que divisam a ideia de progresso e crescimento econômico, tende a orientar os sistemas de ensino pelos Estados nacionais a três finalidades principais: um dispositivo de orientação geral, uma poderosa ferramenta de mobilização ou um formador e disseminador de ideologias (SHANIN, 1997).

Com tal viés, podem-se ladear as potencialidades de uma educação superior com foco no desenvolvimento social, já que sua finalidade esperada passa a ser a de uma ferramenta de controle das massas para um fim específico, e não a de um "instrumento social indutor de melhores possibilidades de subsistência" (ABDI; GUO, 2008, p. 4), capaz de proporcionar mais opçóes às pessoas em relação à sua própria realidade.

Foi assim, com a disseminação e aceitação extensiva da Teoria do Capital Humano (SCHULTZ, 1973; BECKER, 1993) e a forte influência de Organismos Internacionais (OIs), com interesses no setor, tais como Banco Mundial, Fundo Monetário Internacional (FMI) e Banco Internacional para Reconstrução e Desenvolvimento (BIRD), que a educação superior brasileira, a partir da década de 1960, passou a ser vista como o motor das etapas do crescimento econômico e do atendimento aos planos de desenvolvimento social, entrelaçando metodologias 
tipicamente aplicadas ao atendimento isolado de cada um desses diferentes objetivos estatais, como a análise dos custos realizados diante dos benefícios obtidos em relação às demandas sociais (PAIVA, 2001).

Pelo anteriormente exposto e pela análise do Gráfico 1 a seguir, verifica-se que, em 30 anos, se passa do elitismo à massificação da oferta. Mas o ponto a que se orientam mais as atençóes neste texto recai sobre dois questionamentos centrais e complementares: como e em que bases de sustentaçáo esse crescimento ocorreu?

O "como" pode ser facilmente observado cotejando-se a quantidade de instituiçóes privadas, em comparação à quantidade de públicas, com o passar dos anos. Igualmente, ao se confrontar a importância relativa de instituiçóes privadas e públicas para a absorção da grande demanda reprimida pela educação superior, formada pelo longo período de um sistema essencialmente direcionado às elites, pode-se perceber a grande vantagem que as primeiras lograram.

Nesses mesmos 30 anos, por conta da turbulência nos cenários político e social brasileiros, ocorreram grandes alteraçóes no panorama da oferta de vagas para a educação superior. Nesse lapso temporal, o número de Instituiçóes de Ensino Superior (IESs), tanto públicas quanto privadas, apresentou elevação. Contudo, o aspecto mais evidente está nas proporçôes da ascensão tomadas entre uma e outra, pois, se, entre 1980 e 2010, o número de IESs públicas foi ampliado em 39\%, o de IESs privadas alcançou o surpreendente crescimento de 207,9\%. Já o número de alunos matriculados, seguindo a superação pela iniciativa privada iniciada ainda na década de 1960 (SAMPAIO, 2000), parte de uma relação de menos de 2 alunos matriculados em IESs privadas para cada matrícula em IESs públicas na década de 1980 para quase 3 alunos pagantes para cada aluno beneficiado pela educação estatal gratuita em 2010 (Gráfico 2).

\section{Gráfico 1}

Crescimento de matrículas em cursos de graduação - Brasil (1980-2010).

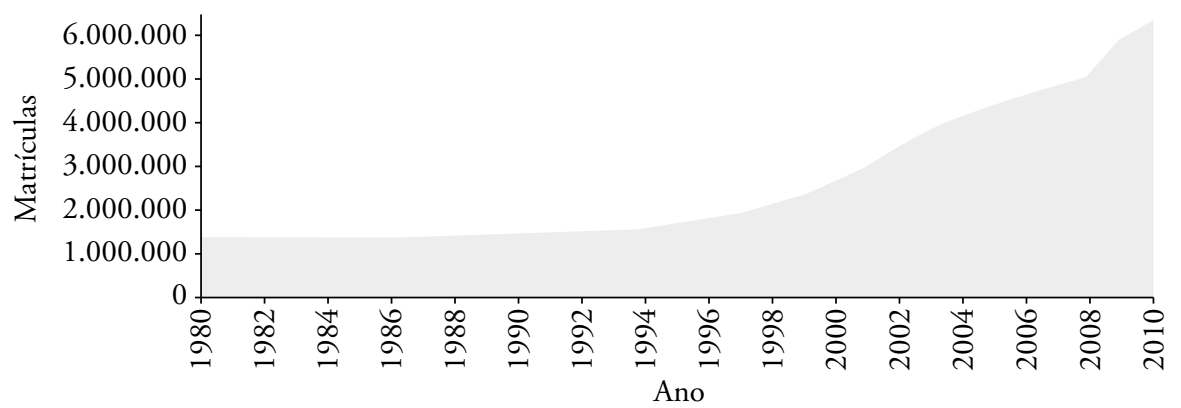

Fonte: MEC/INEP. 
Percebe-se, então, que o salto rumo à massificação da oferta, no caso do Brasil, foi suportado pela junção de dois fatores: os fortes incentivos, ou prioridades, dados à iniciativa privada - quer seja por açóes internas de grupos de interesse (que, motivados pela ambição de um grande potencial de lucros, exerceram pressão sobre os governos no sentido de maior liberalização desse mercado), quer seja pela harmonia das políticas governamentais, oscilantes entre posiçóes ideológicas, composições partidárias e outros fatores intervenientes dessas relaçôes (OLIVEIRA, 2011); e os fortes estímulos externos direcionados à maior diversificação da oferta de vagas, por um modelo misto (público e privado), visando à consequente desoneração financeira estatal, tâo almejada pelo projeto neoliberal, que tal modelo acarreta.

\section{Gráfico 2}

Crescimento do número de Instituiçóes de Ensino Superior e de matrículas em cursos de graduação por categoria administrativa - Brasil (1980-2010).

Número de Instituiçóes de Ensino Superior por Categoria Administrativa

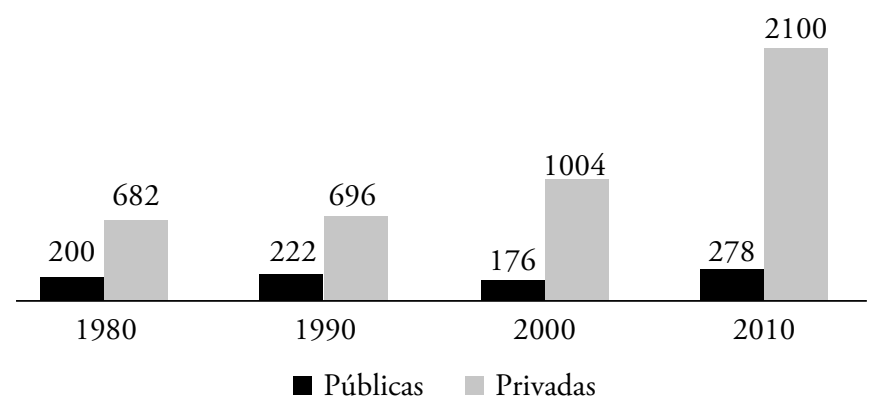

Número de Matrículas no Ensino Superior por Categoria Administrativa

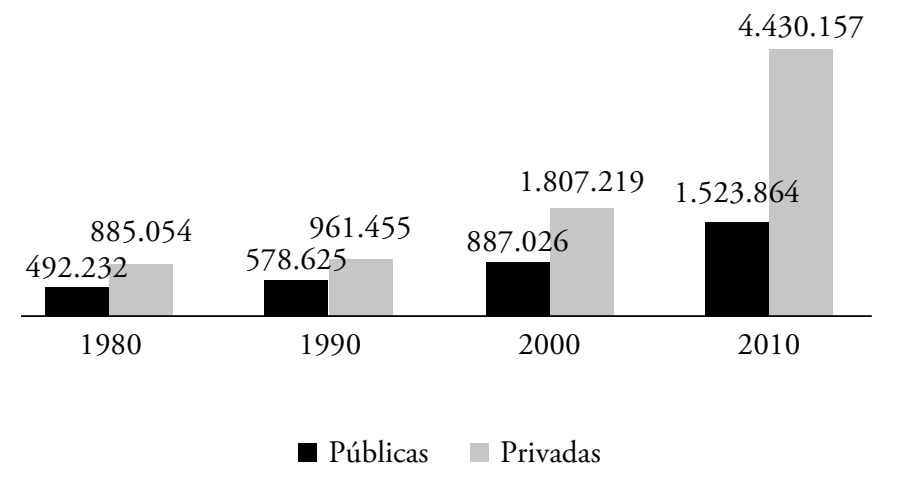

Fonte: $M E C / I N E P$. 
É importante ressaltar que diversos projetos de cunho econômico e desenvolvimentista foram postos em prática no Brasil a partir da década de 1960 pela ação direta de OIs (WILLIAMSON; KUCZYNSKI, 2003) e que tais projetos, invariavelmente, faziam menção a uma necessária redução da participação estatal em áreas sociais consideradas prioritárias (saúde, educação e previdência social, por exemplo) como contrapartida à efetivaçâo de empréstimos financeiros.

Uma peça fundamental dessas políticas foi a constante precarização da educação superior pública, diminuindo sua atração e permitindo que parte da procura se dirigisse ao setor privado. Este, por sua vez, passa a emular o Estado nacional, acenando com as bases da administração científica empresarial, centradas em métodos que supostamente garantem maior eficiência e eficácia no uso dos recursos. Com isso, a iniciativa privada, por sua própria natureza centrada em processos competitivos, confronta a administração das IESs públicas com a forma de gerir das empresas comerciais, escamoteando o verdadeiro sentido das ações ora em marcha, qual seja: a diminuição do Estado que provê em proveito da elevação do Estado que regula e avalia.

\section{O funcionamento da oferta e da escolha}

A visão das IESs como prestadoras de serviços para outros ramos de atividade da sociedade - proposta tanto por OIs quanto por setores internos da economia nacional - exige que essas instituiçóes especializem-se, para atender às mais variadas necessidades, ampliem-se, a fim de atender a grandes massas da população, e autofinanciem-se, ou dependam cada vez menos de verbas públicas, intentando desonerar o Estado.

É, assim, que Brennan (2004), ao abordar o pensamento de Trow (1970) acerca da transição do sistema de educação superior de elite para o sistema de massa e desse para o universal ocorrido no Reino Unido, compila um conjunto de dez dimensôes - "como é percebido, suas funçôes, currículo e formas de instrução, 'carreira' estudantil, diversificação institucional, locus de poder e decisão, padróes acadêmicos, seleção e acesso, administração acadêmica e governança interna" (BRENNAN, 2004, p. 22, traduçâo do autor) - a fim de caracterizar melhor cada um desses três tipos. Não serão exploradas aqui todas as dimensões, pois o objetivo deste texto é bem mais modesto. Serão utilizadas apenas as duas primeiras, conforme a Tabela 1 .

Brennan (2004) verifica, ainda, que, mesmo quando se olha em direção aos "usos" dos sistemas de ensino superior, tanto para as massas quanto para os já universalizados, podem-se ver justificativas predominantemente econômicas em ascendência e muitos debates políticos preocupados com 
açôes que elevem a contribuição das IESs para a economia, produzindo os números necessários de graduados com as habilidades e as competências exigidas pelos empregadores.

Assim, a educação superior de massa brasileira tende a ser percebida como um direito apenas para a parcela da população que pode despender recursos financeiros a fim de garantir seu acesso, quer seja pela passagem por boas escolas básicas que permitam o ingresso por meio dos concorridos exames de seleçáo para as IESs públicas, quer seja pelo pagamento direto às IESs privadas, onde o ingresso é, normalmente, muito menos competitivo.

Jakobi (2007) adota a mesma posição defendida por Brennan (2004) e avança ao discutir o conceito de "educação ao longo da vida" ou, como é mais conhecido no Brasil, "educação continuada". Segundo Jakobi (2007), uma abordagem educacional que, simultaneamente, busque acelerar a obsolescência de saberes já adquiridos e tornar obrigatória a contínua obtenção de novos conhecimentos do tipo formal é de pleno interesse dos grupos de poder que percebem a elevação média da escolarização como necessária para o alcance de seus próprios objetivos. Transfere-se para o cidadáo, retirando do Estado em consequência, o total compromisso por sua própria educação, abarcando nesse movimento não apenas o permanente esforço pessoal para manter-se atualizado, mas seu necessário financiamento.

Dessa forma, uma educação continuada de massa, se posta em prática por essa abordagem, mostra-se potencialmente deletéria aos interesses do cidadáo, na medida em que busca se apoderar de seu tempo e de recursos financeiros pessoais em proveito da pura reproduçáo capitalista ou, como bem aponta Mészáros (2008), em favor do metabolismo próprio de um sistema fundado em bases econômicas.

Outrossim, a existência de um sistema de massa não elimina a de um outro sistema, paralelo, destinado à elite. Argumenta-se que dois sistemas coexistem na realidade brasileira: um que se destina à formação e/ou à manutenção

\section{Tabela 1}

Dimensões da massificação do ensino.

\begin{tabular}{l|c|c|c}
\hline Dimensóes & Elite & Massa & Universal \\
\hline $\begin{array}{l}\text { Como é } \\
\text { percebido o } \\
\text { ensino superior }\end{array}$ & $\begin{array}{c}\text { Um privilégio de } \\
\text { nascimento, talento, } \\
\text { ou ambos. }\end{array}$ & $\begin{array}{c}\text { Um direito para aqueles com } \\
\text { certas qualificaçóes. }\end{array}$ & $\begin{array}{c}\text { Uma obrigação para as } \\
\text { classes média e alta. }\end{array}$ \\
\hline $\begin{array}{l}\text { Quais suas } \\
\text { funçóes }\end{array}$ & $\begin{array}{c}\text { Moldar as mentes e } \\
\text { o caráter da classe } \\
\text { dominante; preparar } \\
\text { para funçóes de elite. }\end{array}$ & $\begin{array}{c}\text { Transmitir competências e } \\
\text { preparar para uma ampla } \\
\text { gama de funçóes técnicas e e } \\
\text { econômicas de elite. }\end{array}$ & $\begin{array}{c}\text { Adaptar a "grande } \\
\text { populaçáo" às rápidas } \\
\text { mudanças sociais e } \\
\text { tecnológicas. }\end{array}$ \\
\hline
\end{tabular}

Fonte: Brennan (2004, p. 22). 
das classes dominantes, formado pelas prestigiadas IESs públicas e algumas poucas instituições privadas mais sofisticadas, como as confessionais; e outro que de fato se destina à grande massa, formado essencialmente por IESs privadas com forte apelo mercadológico, baixo valor de mensalidades e desvinculação da pesquisa científica.

Como comentado, uma eventual diminuição do Estado, enquanto exclusivo provedor de educação, abre espaço para o tratamento desta como puro serviço, tal como defendido pela Organização Mundial do Comércio ( $\mathrm{OMC}$ ). Um dos efeitos colaterais de uma educação percebida como puro serviço, a seu turno, está em que ela passa a ser regida pelas leis econômicas do mercado, basicamente oferta e demanda. É, nesse aspecto em particular, que reside a crueldade para com as classes mais baixas, pois um sistema de ensino regulado por oferta e demanda de serviços tende a eleger, ele próprio, bons fornecedores (habilitados a cobrar preços premium por ofertas superiores), fornecedores medianos (mais afetados por fatores como concorrência, localização, etc.) e, ainda, fornecedores ditos "de massa" (para os quais os fatores custo de produção, quantidade de alunos e preço praticado são determinantes para manutenção de suas atividades).

Forma-se, desse modo, um mercado educacional que se autossegmenta em uma galeria diversificada de IESs, para tipos diferentes de públicos, com distintos critérios e percepçóes de qualidade para suas ofertas.

Um posicionamento neoliberal a esse respeito afirmaria que a escolha individual cabe ao cidadão, já que todas as ofertas possíveis foram postas. A esse respeito, Olssen, Codd e O'Neill (2004) sustentam que a possibilidade de escolha tem se tornado a base das grandes reformas educacionais e continuam - utilizando o exemplo neozelandês - afirmando que não existem claras evidências de uma redução das desigualdades sociais pelo pleno exercício da liberdade de escolha, definindo esse termo como "o exercício de escolhas racionais e individualizadas em um livre mercado” (OLSSEN; CODD; O’NEILL, 2004, p. 199).

Ora, parece evidente, concordando com Brennan (2001), que, se indivíduos utilizam seus critérios subjetivos de preferência para a escolha de uma IES, compostos pela imagem e pelos valores percebidos da instituição, dos custos e da localização; e que se tais critérios são o resultado de suas interaçóes sociais e possibilidades financeiras e de deslocamento; não existem, de fato, tantas opções individuais possíveis para a grande massa populacional das camadas mais baixas.

Verifica-se, assim, que candidatos com melhores condiçóes financeiras e níveis socioculturais mais elevados tendem a concentrar-se nas IESs públicas e privadas mais sofisticadas (percebidas como superiores), ao passo que alunos das camadas menos favorecidas são, consequentemente, empurrados para IESs 
particulares com atuação mais mercantil. Eis que a reprodução de classes se configura no seio da educação superior, de forma que esta pode ser entendida como opressora.

\section{O potencial opressor da massificação}

Pode-se dizer que um dos objetivos centrais das políticas de governo após a década de 1980, no que tange ao ensino superior, qual seja, a garantia da oferta de vagas para a grande massa da população até então excluída, foi alcançado com êxito, já que, no Brasil, há vários anos, a oferta de vagas tem superado em números a quantidade de matrículas efetivas, demonstrando a ociosidade do sistema. Entretanto, o problema que ora se discute é outro: como os diferentes grupos sociais, com demandas distintas, tendem a se comportar diante dessa diversidade de ofertas formada a partir do modelo de expansão adotado?

Compreende-se que grupos sociais com melhores condições econômicas e culturais tendem a oprimir, no interior do complexo sistema de educação superior, grupos sociais das camadas mais inferiores, com o intuito de manter inalteradas as bases sociais de divisão de classes e mobilidade. A fim de explicar melhor esse posicionamento, devem ser mais bem definidos os termos opressão e grupo social.

Salas de aula e escolas representam uma "cultura de poder" na medida em que espelham injustas relaçôes sociais existentes na sociedade mais ampla (APPLEBAUM, 2003, p. 151). Para Young (1990), que discute as políticas destinadas à eliminação de diferenças, as principais causas de injustiça social, analisando o problema pelo seu inverso, são a opressão e a dominação que grupos de poder exercem em relação a grupos menores. Ainda, segundo a autora, esses conceitos se sobrepóem, de forma que onde se configura a opressão também existe um sistema de dominação. Pode-se caracterizar a opressão, diante de tais argumentos, pela inibição das capacidades para desenvolver e exercitar potencialidades, expressar necessidades, pensamentos e sentimentos entre diferentes grupos sociais. Desse modo, a opressão representa, segundo Young (1990), um achatamento ou uma contenção de grupos sociais no interior de um sistema de dominação que atua por força de cinco faces, sendo elas: exploração, marginalização, enfraquecimento, colonialismo cultural e violência.

Como destacado neste artigo, a massificação privada da educação superior brasileira decorreu, em grande parte, de incentivos e do apoio de políticas governamentais de cunho neoliberal, visando à desoneração do Estado. Nesse contexto, como preconiza essa corrente em sua vertente econômica, os méritos do esforço individual, "variável interveniente que se distribui de forma naturalmente desigual na população" (FREITAS, 2007, p. 968), devem sobrepor-se aos méritos 
do grupo. Obviamente, tal abordagem tem forte potencial deletério aos interesses dos cidadáos que encontram, justamente no fato de participarem de algum grupo social, o apoio para renunciar às várias formas de opressão.

Por sua vez, um grupo social não é uma entidade que se sobrepõe ao indivíduo e dele independe para existir. Um grupo social, definido por Fiss (1976), representa uma classificação arbitrária de indivíduos organizados de acordo com atributos externalizáveis ou ocasionais que formam potencialmente suas próprias identidades. Nesse sentido, interessa um tipo específico de grupo social, identificado por Young (1990), que se forma a partir da exclusão de outro agrupamento. Os excluídos, rotulados como uma categoria distinta de pessoas e usualmente inferiorizados, lenta e debilmente, passam a entender-se como novos partícipes de outro conjunto, que se reúne em torno de uma determinada face da opressão que foi sofrida de forma compartilhada por seus membros.

Criam-se, assim, em um ambiente formado por microssistemas de cotas, exames de ingresso, programas de crédito estudantil, rankings e tantos outros, três grandes grupos no âmbito da educação superior, segmentados, basicamente, para ricos, pobres e pobres assistidos; explicando melhor esses dois últimos, segundo Castel (2012): os que preenchem os requisitos de filiação a algum programa de equidade estatal recebem, graças a isso, assistência, e os que não preenchem carecem de tal assistência.

Há de se concordar com Guimarães-Iosif e Santos (2012) quando concluem que o modelo de política e governança da educação superior brasileira necessita ser alterado, sob pena de ser direcionado apenas para interesses mercadológicos, comprometendo o próprio projeto democrático e emancipatório do país.

A opressão, retornando ao tema, apresenta-se desde o nascimento dos indivíduos, classificando-os em grupos distintos e acompanha-os pelos ensinos fundamental e médio, podendo abrandar-se ou aprofundar-se ainda mais, chegando, com mais força, aos estudos superiores, determinando classes de cursos e tipos de escolas para pessoas e interesses distintos; de modo que poderá manter-se por toda a vida do cidadáo, interferindo na escolha de tarefas a serem desempenhadas na sociedade.

Sugere-se, também, que a função de um sistema de educação superior, organizado da maneira como se tem descrito e defendido ao longo do texto, é garantir a permanência dos grupos de controle em posiçôes privilegiadas, já que, pela face opressora da marginalizaçáo, conforme apontado, todo o tecido social se prepara para rotular os indivíduos que se apresentam por um passado acadêmico em virtude do qual, ainda de acordo com o exposto, muito pouco puderam arbitrar. Eis que a falácia da escolha individual, fortemente sustentada pelo pensamento neoliberal, se apresenta com todo seu vigor. 


\section{Considerações Finais}

Considera-se, entre outros aspectos, que uma educação verdadeiramente cidadã seria pautada pela formação de indivíduos capazes de fugir das amarras da reprodução social e, por si mesmos, buscar formas de satisfação de seus próprios e subjetivos estados de bem-estar. Entretanto, um modelo de expansão da educação superior estruturado em bases predominantemente privadas, com políticas governamentais direcionadas unicamente para o lado da oferta, sem mesmo entender as necessidades dos seus demandantes, tende a criar opressão entre grupos de poder em seu interior.

A instituição de educaçáo superior náo pode ser percebida ou tratada como imune às variaçóes sociais que ocorrem em torno de si. Antes disso, ela compóe esse cenário atuando ora como libertadora, ora como opressora de determinados grupos sociais.

A diversificação estrutural da educação superior brasileira, formada por tendências claramente neoliberais e direcionadas ao atendimento, o mais rápido possível, às crescentes demandas de um mercado global e liberalizado, funciona como uma grande máquina opressora para grupos já excluídos socialmente.

Seu poder de achatamento e manutençáo das desigualdades sociais cresce sem precedentes em uma sociedade que, cada vez mais, demanda indivíduos adaptados a rápidas mudanças ambientais. A diminuição do papel do Estado nesse processo auxilia a versão continuísta do controle de poder nas mãos dos mesmos grupos, elitistas, que sempre o tiveram, impedindo a mobilidade social.

Observa-se que a grande falácia da liberdade de escolha, partindo do pressuposto de que, em uma estrutura diversificada como a que ora se apresenta, existem opçóes suficientes para a adequação às necessidades ou às expectativas de cada indivíduo, desconsidera a interconexão da instituição de educação superior com outras instituiçóes sociais e mesmo a interconexão entre os diversos grupos em seu interior.

Assim, em tal modelo, não há como se crer que as diferenças sociais possam ser diminuídas. Antes, esse ideal preza pela diferenciação de usos do produto final da educação superior, evidenciando a incompatibilidade pela distinção daquilo que é considerado útil para o capital e para os interesses de pequenos grupos e relegando para as massas a diferença.

Indica-se, então, que uma solução válida para a educação superior destinada a grandes públicos, massificada em sua essência, requer que o lado da demanda, pelos diferentes grupos sociais, seja privilegiado em detrimento da pura e simples oferta de vagas. A educação superior deve ser preparada para servir a grandes grupos sociais, e não a poucos interesses, geralmente econômicos. Enfim, que ela atue como libertadora de amarras, e não, ela própria, como opressora. 


\section{Nota}

1. É Trow (1970) quem melhor descreve as funçôes do ensino superior em suas três formas. Assim, para o melhor entendimento deste texto, deve-se considerar que sistemas de educação superior: (i) devotados às elites: visam moldar a mente e o caráter de uma classe dominante e garantir a perpetuidade de sua condição de comando; (ii) os sistemas voltados às massas: buscam a transmissão de competências com vistas à preparação para uma ampla gama de funções demandadas pelas elites técnicas e econômicas; (iii) e os sistemas de educação universalizados: proporcionam possibilidades de adaptação de "toda a populaçáo" às rápidas mudanças sociais e tecnológicas.

\section{Referências}

ABDI, A.A.; GUO, S. Education and social development: an introduction. In: . (Orgs.). Education and social developments: global issues and analyses. Rotterdam: Sense Publishers, 2008, p. 3-12.

APPLEBAUM, B. Social justice, democratic education and the silencing of words that wound. Journal of Moral Education, v. 32, n. 2, p. 151-162, 2003.

BECKER, G.S. Human capital: a theoretical and empirical analysis with special reference to education. Chicago: The University of Chicago Press, 1993.

BRENNAN, J. The social role of the contemporary university: contradictions, boundaries and change. In: CHERI. Ten years on: changing education in a changing world. Milten Keines, Enland: Open University, 2004, p. 22-26. Disponível em: $\leq$ http://www.open. ac.uk/cheri/documents/ten-years-on.pdf>. Acesso em: 3 set. 2012.

BRENNAN, L.-M. How prospective students choose universities: a buyer behaviour perspective. Tese (Doutorado) - Centre for the Study of Higher Education, University of Melbourne, Melbourne, 2001. Disponível em: <http://repository.unimelb.edu. au/10187/2873>. Acesso em: 20 ago. 2012.

CARDINAL NEWMAN, J.H. The idea of a university defined and illustrated. New York: Longmans Green and Co., 1873. Disponível em: shttp://archive.org/details/ ideaauniversity03newmgoog $>$. Acesso em: $1 .^{\circ}$ set. 2012.

CASTEL, R. As metamorfoses da questão social: uma crônica do salário. Petrópolis: Vozes, 2012.

FISS, O. Groups and the equal protection clause. Philosophy \& Public Affairs, New Haven, Connecticut, v. 5, n. 2, p. 107-177, 1976. Disponível em: <http://www.jstor.org/ stable/2264871>. Acesso em: 5 set. 2012.

FLEXNER, A. Universities: American English German. New York: Oxford University Press, 1930. Disponível em: <http://archive.org/details/universitiesamer008115mbp $>$. Acesso em: 1. ${ }^{\circ}$ set. 2012. 
FREITAS, L.C. Eliminação adiada: o caso das classes populares no interior da escola e a ocultação da (má) qualidade do ensino. Educação e Sociedade, Campinas, v. 28, n. 100, p. 965-987, 2007. Edição Especial. Disponível em: <http://www.scielo.br/pdf/es/ v28n100/a1628100.pdf >. Acesso em: 20 ago. 2012.

GUIMARÃES-IOSIF, R.; SANTOS, A.V. A governança contemporânea na educação superior brasileira: atores, disputas e desafios. In: (Org.). Politica e governança educacional: contradições e desafios na promoção da cidadania. Brasília: Liber Livro/ Universa, 2012, p. 99-128.

JAKOBI, A.P. Converging agendas in education policy: lifelong learning in the World Bank and the International Labour Organization. In: MARTENS, K.; RUSCONI, A.; LEUZE, K. (Orgs.). New arenas of education governance: the impact of international organizations and markets on educational policy making. Eastbourne: Palgrave Macmillan, 2007, p. 95-114.

KERR, C. The uses of the university. New York: Harper Torchbooks, 1966.

LOBO, R.L. Os desafios do mercado e o futuro da educação superior: prospecção dos cenários para os diferentes tipos de IES. In: CUNHA, C.; SOUSA, J.V.; SILVA, M.A. (Orgs.). Políticas públicas de educação na América Latina: lições aprendidas e desafios. Campinas: Autores Associados, 2011, p. 147-164.

MÉSZÁROS, I. A educação para além do capital. São Paulo: Boitempo, 2008.

OLIVEIRA, D.A. Das políticas de governo à política de estado: reflexóes sobre a atual agenda educacional Brasileira. Educação e Sociedade, Campinas, v. 32, n. 115, p. 323-337, 2011. Disponível em: <http://www.scielo.br/scielo.php?script=sci $\operatorname{arttext\& pid=S0101-}$ $73302011000200005 \& \operatorname{lng}=$ pt\&nrm=iso $>$. Acesso em: 10 set. 2012.

OLSSEN, M.; CODD, J.; O’NEILL, A.-M. Education policy: globalization, citizenship and democracy. Gateshead, England: Sage Publications, 2004.

PAIVA, V. Sobre o conceito de "capital humano". Caderno de Pesquisas, São Paulo, n. 113, p. 185-191, 2001. Disponível em: <http://www.scielo.br/scielo.php?script=sci arttext\&pid=S0100-15742001000200010\&lng=en\&nrm=iso $>$. Acesso em: 3 set. 2012.

SAMPAIO, H. Ensino superior no Brasil: o setor privado. São Paulo: Fapesp/Hucitec, 2000.

SCHULTZ, T.W. O valor econômico da educaçâo. Rio de Janeiro: Zahar, 1973.

SERAFIM, M.P. O processo de mercantilização das instituições de educação superior: um panorama do debate nos EUA, na Europa e na América Latina. Avaliação (Campinas), Sorocaba, v. 16, n. 2, p. 241-265, 2011. Disponível em: <http://www.scielo.br/scielo. php? script $=$ sci arttext $\&$ pid $=\$ 1414-40772011000200002 \& \operatorname{lng}=$ pt $\& n r m=$ iso $>. \quad$ Acesso em: 10 set. 2012.

SHANIN, T. The idea of progress. In: RAHNEMA, M.; BAWTREE, V. The post development reader. New Jersey: Zed Books, 1997, p. 65-72.

TROW, M. Reflections on the transition from mass to universal higher education. Daedalus, Cambridge, Massachusetts, v. 99, n. 1, p. 1-42, 1970. Disponível em: shttp://www.jstor.org/stable/20023931>. Acesso em: 30 ago. 2012. 
WEIS, L.; DOLBY, N. Social class and education: global perspectives. New York: Routledge Academic, 2012.

WILLIAMSON, J.; KUCZYNSKI, P.-P. After the Washington consensus: restarting growth and reform in Latin America. Washington: Institute for International Economics, 2003.

YOUNG, I.M. Justice and the politics of difference. Princeton: Princeton University Press, 1990.

Recebido em 11 de setembro de 2012.

Aprovado em 19 de janeiro de 2017. 